\title{
Prevalence of Hyperuricemia and Gout in Mainland China from 2000 to 2014: A Systematic Review and Meta-Analysis
}

\author{
Rui Liu, Cheng Han, Di Wu, Xinghai Xia, Jianqiu Gu, Haixia Guan, \\ Zhongyan Shan, and Weiping Teng \\ Department of Endocrinology and Metabolism, The Endocrine Institute and The Liaoning Provincial Key Laboratory of \\ Endocrine Diseases, The First Affiliated Hospital of China Medical University, Shenyang, Liaoning 110001, China
}

Correspondence should be addressed to Haixia Guan; hxguan@vip.126.com and Weiping Teng; twp@vip.163.com

Received 20 August 2015; Revised 20 October 2015; Accepted 25 October 2015

Academic Editor: Lorenzo Cavagna

Copyright (c) 2015 Rui Liu et al. This is an open access article distributed under the Creative Commons Attribution License, which permits unrestricted use, distribution, and reproduction in any medium, provided the original work is properly cited.

\begin{abstract}
We systematically identified the prevalence of hyperuricemia and gout in mainland China and provided informative data that can be used to create appropriate local public health policies. Relevant articles from 2000 to 2014 were identified by searching 5 electronic databases: PubMed, Google Scholar, Chinese Wanfang, CNKI, and Chongqing VIP. All of the calculations were performed using the Stata 11.0 and SPSS 20.0 software. The eligible articles ( $n=36 ; 3$ in English and 33 in Chinese) included 44 studies (38 regarding hyperuricemia and 6 regarding gout). The pooled prevalence of hyperuricemia and gout was 13.3\% (95\% CI: 11.9\%, 14.6\%) and $1.1 \%$ (95\% CI: $0.7 \%, 1.5 \%)$, respectively. Although publication bias was observed, the results did not change after a trim and fill test, indicating that that impact of this bias was likely insignificant. The prevalence of hyperuricemia and gout was high in mainland China. The subgroup analysis suggested that the geographical region, whether the residents dwell in urban or rural and coastal or inland areas, the economic level, and sex may be associated with prevalence.
\end{abstract}

\section{Introduction}

Serum uric acid is the final enzymatic product of purine metabolism [1, 2]. Abnormalities in serum uric acid metabolism may cause hyperuricemia and gout. Hyperuricemia is the result of interactions among multiple factors, including sex, age, genetics, lifestyle, and environment [3]. Several studies have suggested that hyperuricemia is associated with many diseases, including diabetes mellitus [4], hypertension [5, 6], stroke [2, 7], dyslipidemia [8], chronic kidney disease [9], cardiovascular events, and heart failure [10-12]. Hyperuricemia is considered to be a precursor of gout as the deposition of urate crystals in the joints results in an acute inflammatory response. Deposition in the soft tissue can lead to tophi [13-15]. Gout is also a serious health issue and is an independent risk factor for heart failure and metabolic syndrome $[16,17]$. In recent years, an increasing trend in the prevalence of hyperuricemia and gout has been observed in epidemiological studies [13, 18-21], and both diseases have become public health problems that need to be solved quickly.
Due to rapid economic development, the lifestyle of the Chinese has changed greatly, a huge transition from a dietary pattern traditionally based on carbohydrates and vegetables to a pattern that relies on meat, dairy products, and other purine-rich foods that are closely related to hyperuricemia and gout $[22,23]$.

As a large developing country, China has marked regional differences and varied populations. To date, most investigations have been limited to certain areas or have focused on specific occupations. Therefore, a comprehensive study on the epidemiology of hyperuricemia and gout in the entire mainland China is needed. As most of the published data are in Chinese, we present our study in the widely read English medium. Obtaining an accurate prevalence of hyperuricemia and gout is important to help us formulate appropriate local public health policies. In addition, such a study will benefit the people through health education by increasing awareness of hyperuricemia and gout and also the importance of improving lifestyle and maintaining a healthy diet. 
Due to varied geographic locations that include diverse populations and different socioeconomic conditions, a unified epidemiological investigation about the prevalence of hyperuricemia and gout remains difficult. We conducted a meta-analysis regarding the prevalence of both diseases in mainland China between January 2000 and December 2014 to determine the epidemiology and to review the results from previous studies.

\section{Methods}

2.1. Search Strategy. We manually searched all of the literatures regarding population-based research on the prevalence of hyperuricemia and gout from 2000 to 2014 using the PubMed, Google Scholar, CNKI (Chinese National Knowledge Infrastructure), Chinese Wangfang, and Chongqing VIP electronic databases. The keywords for search were "uric acid," "HUA," "HU," "hyperuricemia," "gout," "prevalence(s)," "incidence(s)," and "epidemiology." To find additional studies, the reference lists of the identified studies were also examined.

2.2. Inclusion and Exclusion Criteria. Papers were included if they met all of the following criteria: (1) all study participants living in mainland China; (2) study data being general population-based rather than hospital-based; (3) prevalence rate being also analyzed by according to sex; (4) accurate diagnostic criteria and clear study date; and (5) the most detailed study of duplicate studies on the same population.

Studies were excluded if they (1) were not original research, such as a review or case report, (2) included participants with concomitant diseases or had medication history known to affect uric acid metabolism, or (3) focused on specific population groups, such as teenagers, elderly people, or single gender, or a certain occupation.

2.3. Definition of Hyperuricemia and Gout. The diagnostic criteria for hyperuricemia varied among the studies; we have listed each criterion in Table 1 . The diagnostic criteria for gout were listed in Table $2[24,25]$.

2.4. Data Extraction. Two reviewers searched the literature independently. Any disagreement on data extraction between the two reviewers was mediated by discussion [26]. Figure 1 shows the literature-search process. We recorded the characteristics of all the included papers in Table 1, including the title, author's name, publication date, study year, study population, geographic area, rural/urban, inland/coastal, sample size, case, prevalence, and diagnostic criterion.

2.5. Statistical Analysis. Pooled prevalence and 95\% confidence intervals (CIs) were calculated to estimate the prevalence of hyperuricemia and gout in mainland China. We adopted the Chi-squared-based $Q$ test and the $I^{2}$ test to evaluate the heterogeneity of the studies; $25 \%, 50 \%$, and $75 \%$ were considered low, moderate, and high levels, respectively $[27,28]$. If the level of heterogeneity was moderate or high, we used a random-effects meta-analysis model instead of a fixed-effects model. To perform a secondary analysis and to address heterogeneity, a subgroup analysis was required.
Egger's test was used to estimate publication bias. A $P$ value less than 0.05 was considered statistically significant. Metaanalysis was calculated using Stata Version 11.0 (Stata Corp LP, College Station, TX, USA). Significant differences in prevalence among the groups were examined through the Chi-square test using SPSS Version 20.0 (SPSS Software, Chicago, IL, USA). All figures were generated using Stata 11.0 (Stata Corp LP, College Station, TX, USA) or Microsoft PowerPoint (Microsoft, Redmond, USA).

\section{Results}

3.1. Characteristics of Included Studies. A total of 604 articles were identified (Figure 1). After screening for population base, study type, relevancy, and duplicates, 36 literary papers (3 in English and 33 in Chinese) containing 44 studies (38 regarding hyperuricemia and 6 regarding gout) met our inclusion criteria. A detailed description of these studies is provided in Table 1.

3.2. Pooled Prevalence of Hyperuricemia and Gout. As shown in Figure 2, the pooled prevalence of hyperuricemia was $13.3 \%$ (95\% CI: $11.9 \%, 14.6 \%$ ), with the prevalence ranging from $5.5 \%$ to $23.6 \%$. As shown in Figure 3, the pooled prevalence of gout was $1.1 \%$ (95\% CI: $0.7 \%, 1.5 \%)$, with a range of $0.4-1.5 \%$.

Figures 4 and 5 showed the individual prevalence of hyperuricemia and gout, respectively, in different provinces, municipalities, and autonomous regions.

3.3. Subgroup Analysis. The prevalence of hyperuricemia in mainland China was analyzed in subgroups, which were separated based on the following categories: rural or urban, coast or inland, location (north, south, northwest, northeast, and southwest China), economic level, and sex. As shown in Table 3, location in an urban area $\left(\chi^{2}=25.53, P<\right.$ $0.001)$, inland area $\left(\chi^{2}=117.95, P<0.001\right)$, or south China $\left(\chi^{2}=507.39, P<0.001\right)$ and a high economic level $\left(\chi^{2}=8.40, P=0.004\right)$ might indicate a high prevalence of hyperuricemia. Notably, sex may also be closely associated with hyperuricemia prevalence, as the prevalence among men and women was $19.4 \%$ (95\% CI: $17.6 \%, 21.1 \%)$ and $7.9 \%(95 \%$ CI: $6.6 \%, 9.3 \%)$, respectively.

For gout, the prevalence among the subgroups was very different (Table 4). Urban residents had a much higher prevalence of gout $(1.2 \%, 95 \% \mathrm{CI}: 0.7 \%, 1.8 \%)$ compared with rural residents $\left(0.9 \%, 95 \% \mathrm{CI}: 0.2 \%, 1.6 \% ; \chi^{2}=19.96, P<\right.$ $0.001)$. Inland area residents had a higher prevalence of gout $(1.4 \%, 95 \%$ CI: $0.8 \%, 1.9 \%)$ than coastal area residents $(0.8 \%$, 95\% CI: $\left.0.2 \%, 1.4 \% ; \chi^{2}=23.88, P<0.001\right)$. An increasing prevalence of gout was seen over the years; $0.9 \%$ (95\% CI: $0.0 \%, 1.8 \%$ ) of subjects investigated from 2000 to 2005 were diagnosed with gout, and this number increased to $1.4 \%(95 \%$ CI: $0.5 \%, 2.2 \%)$ after $2010\left(\chi^{2}=7.47, P=0.024\right)$. Regarding sex, the prevalence rate was $1.5 \%$ (95\% CI: $0.8 \%, 2.1 \%)$ in men and $0.9 \%$ (95\% CI: $0.0 \%, 1.0 \%)$ in women.

3.4. Analysis of Heterogeneity and Publication Bias. A significant overall heterogeneity was noted in the study on 
TABLE 1: Characteristics of studies on the prevalence of hyperuricemia and gout.

\begin{tabular}{|c|c|c|c|c|c|c|c|c|c|}
\hline First author & $\begin{array}{c}\text { Publication } \\
\text { year }\end{array}$ & Area & $\begin{array}{c}\text { Diagnostic } \\
\text { criterion }(\mu \mathrm{mol} / \mathrm{L}) \\
(\text { Men/Women })\end{array}$ & $\begin{array}{l}\text { Rural/ } \\
\text { urban }\end{array}$ & $\begin{array}{l}\text { Inland/ } \\
\text { coastal }\end{array}$ & $\begin{array}{l}\text { Study } \\
\text { year }\end{array}$ & $\begin{array}{l}\text { Sample } \\
\text { size }\end{array}$ & Case & $\begin{array}{c}\text { Prevalence } \\
(\%)\end{array}$ \\
\hline \multicolumn{10}{|c|}{ Prevalence of hyperuricemia } \\
\hline Shi [29] & 2013 & Shijingshan, Beijing & $\geq 420 / \geq 350$ & Urban & Inland & 2012 & 3961 & 438 & 11.06 \\
\hline $\mathrm{Ma}[30]$ & 2014 & Xichengqu, Beijing & $\geq 417 / \geq 357$ & Urban & Inland & 2012 & 834 & 100 & 11.99 \\
\hline $\operatorname{Li}[31]$ & 2013 & Bortala, Xinjiang & $>420 />350$ & Rural & Inland & 2009 & 2046 & 261 & 12.76 \\
\hline Zheng [32] & 2010 & Wenzhou, Zhejiang & $\geq 417 / \geq 357$ & Urban & Inland & 2008 & 1520 & 114 & 7.50 \\
\hline Sun [33] & 2008 & Dalian, Liaoning & $\geq 420 / \geq 350$ & Rural & Coastal & 2007 & 1024 & 100 & 9.77 \\
\hline Hou [34] & 2010 & Dalian, Liaoning & $>420 />350$ & Rural & Coastal & 2007 & 1021 & 97 & 9.50 \\
\hline Wang [35] & 2010 & Baoshan, Yunnan & $>420 />350$ & Urban & Coastal & 2009 & 1501 & 210 & 13.99 \\
\hline $\mathrm{Yu}[36]$ & 2010 & Foshan, Guangdong & $\geq 417 / \geq 357$ & Urban & Coastal & 2008 & 7403 & 1117 & 15.09 \\
\hline Wu [37] & 2008 & Guangzhou, Guangdong & $\geq 417 / \geq 357$ & Urban & Inland & 2007 & 2788 & 578 & 20.73 \\
\hline Zou $[38]$ & 2011 & Guilin, Guangxi & $\geq 420 / \geq 360$ & Urban & Inland & 2009 & 6273 & 1477 & 23.55 \\
\hline Wang [39] & 2008 & Zhoushan, Zhejiang & $>420 />360$ & Rural & Inland & 2007 & 1438 & 158 & 10.99 \\
\hline Meng [40] & 2012 & Gaoyou, Jiangsu & $\geq 420 / \geq 360$ & Rural & Inland & 2010 & 4504 & 538 & 11.94 \\
\hline Shen [41] & 2014 & Wuxi, Jiangsu & $\geq 417 / \geq 357$ & Urban & Inland & 2009 & 3723 & 754 & 20.25 \\
\hline Song [42] & 2014 & Nanchang, Jiangxi & $>420 />350$ & Urban & Inland & 2011 & 3795 & 795 & 20.95 \\
\hline Shao [43] & 2003 & Nanjing, Jiangsu & $\geq 417 / \geq 357$ & Urban & Inland & 2003 & 7778 & 1038 & 13.35 \\
\hline Zhou [44] & 2013 & Ningbo, Zhejiang & $>420 />370$ & Urban & Coastal & 2008 & 2110 & 190 & 9.00 \\
\hline Huang [45] & 2013 & Ningbo, Zhejiang & $>420 />360$ & Urban & Coastal & 2012 & 1754 & 195 & 11.12 \\
\hline Xin [46] & 2013 & Qingdao, Shandong & $>420 />350$ & Urban & Coastal & 2011 & 5165 & 748 & 14.48 \\
\hline Tian [47] & 2008 & Qingdao, Shandong & $>420 />350$ & Urban & Coastal & 2006 & 2363 & 471 & 19.93 \\
\hline Tian [47] & 2008 & Qingdao, Shandong & $>420 />350$ & Rural & Coastal & 2006 & 2467 & 405 & 16.42 \\
\hline Dong [48] & 2004 & Qingdao, Shandong & $>420 />350$ & Urban & Coastal & 2002 & 2190 & 402 & 18.36 \\
\hline Zhang [49] & 2006 & Haiyang, Shandong & $>416.36 />356.88$ & Rural & Coastal & 2004 & 5372 & 649 & 12.08 \\
\hline Wang [50] & 2010 & Shenyang, Liaoning & $>420 />350$ & Urban & Inland & 2009 & 675 & 78 & 11.56 \\
\hline Chen [51] & 2008 & Chengdu, Sichuan & $\geq 428$ & Urban & Inland & 2006 & 2566 & 400 & 15.59 \\
\hline Guo [52] & 2012 & Taiyuan, Shanxi & $\geq 420$ & Urban & Inland & 2010 & 4228 & 371 & 8.77 \\
\hline Wang [53] & 2010 & Wenzhou, Zhejiang & $>420 />350$ & Urban & Coastal & 2008 & 3478 & 260 & 7.48 \\
\hline Shao [54] & 2011 & Wenzhou, Zhejiang & $>420 />350$ & Urban & Coastal & 2008 & 3480 & 260 & 7.47 \\
\hline Pan [55] & 2014 & Changzhou, Jiangsu & $>420 />380$ & Rural & Inland & 2008 & 3122 & 573 & 18.35 \\
\hline Duan [56] & 2013 & Korla, Xinjiang & $>417 />357$ & Urban & Inland & 2009 & 2046 & 261 & 12.76 \\
\hline Zhang [57] & 2014 & Xingtai, Hebei & $>420 />350$ & Rural & Inland & 2013 & 2109 & 177 & 8.39 \\
\hline Mou [58] & 2013 & Yantai, Shandong & $\geq 380$ & Urban & Coastal & 2012 & 635 & 66 & 10.39 \\
\hline Li [59] & 2010 & Yan’an, Shaanxi & $>417 />357$ & Urban & Inland & 2008 & 1290 & 71 & 5.50 \\
\hline Chen [60] & 2009 & Dali, Yunnan & $>420 />350$ & Urban & Inland & 2006 & 7505 & 923 & 12.30 \\
\hline Jin [61] & 2009 & Zhuhai, Guangdong & $>420 />360$ & Rural & Coastal & 2007 & 1112 & 164 & 14.75 \\
\hline Cai [62] & 2009 & Hangzhou, Zhejiang & $>420 />360$ & Urban & Inland & 2008 & 4155 & 702 & 16.90 \\
\hline You [63] & 2014 & Mongolian & $\geq 416 / \geq 357$ & Urban & Inland & 2009 & 630 & 120 & 19.05 \\
\hline You [63] & 2014 & Mongolian & $\geq 416 / \geq 357$ & Rural & Coastal & 2009 & 179 & 23 & 12.85 \\
\hline Zhang [64] & 2011 & Tianjin & $>420 />360$ & Urban & Coastal & 2009 & 17762 & 2160 & 12.16 \\
\hline \multicolumn{10}{|c|}{ Prevalence of gout } \\
\hline Yu [36] & 2010 & Foshan, Guangdong & - & Urban & Coastal & 2008 & 7403 & 77 & 1.04 \\
\hline $\mathrm{Wu}[37]$ & 2008 & Guangzhou, Guangdong & - & Urban & Inland & 2007 & 2788 & 40 & 1.43 \\
\hline Song [42] & 2014 & Nanchang, Jiangxi & - & Urban & Inland & 2011 & 3795 & 58 & 1.53 \\
\hline Shao [43] & 2003 & Nanjing, Jiangsu & - & Urban & Inland & 2003 & 7778 & 105 & 1.35 \\
\hline Zhang [49] & 2006 & Haiyang, Shandong & - & Rural & Coastal & 2004 & 5372 & 23 & 0.43 \\
\hline Zhang [57] & 2014 & Xingtai, Hebei & - & Rural & Inland & 2013 & 2109 & 26 & 1.23 \\
\hline
\end{tabular}


TABLE 2: Gout classification criteria.

Yu et al. [36]

Classification criteria for gout [25]

(1) More than one attack of acute arthritis

(2) Maximum inflammation developed within 1 day

(3) Oligoarthritis attack

(4) Redness observed over joints

(5) First MTP joint painful or swollen

(6) Unilateral first MTP joint attack

(7) Unilateral tarsal joint attack

(8) Tophus (suspected or proven)

(9) Hyperuricemia (more than 2 S.D. greater than the normal population average)

(10) Asymmetric swelling within a joint on X-ray

(11) Complete termination of an attack

Case definition: $\geq 6$ of 11 clinical criteria
Wu et al., Song et al., Shao et al., Zhang et al., and Zhang et al. [37, 42, 43, 49, 57]

ARA preliminary classification criteria for acute gout 1977 [24]

(1) More than one attack of acute arthritis

(2) Maximum inflammation developed within 1 day

(3) Oligoarthritis attack

(4) Redness observed over joints

(5) First MTP joint painful or swollen

(6) Unilateral first MTP joint attack

(7) Unilateral tarsal joint attack

(8) Tophus (suspected or proven)

(9) Hyperuricemia (more than 2 S.D. greater than the normal population average)

(10) Asymmetric swelling within a joint on X-ray

(11) Subcortical cysts without erosions on X-ray

(12) Complete termination of an attack

Case definition: $\geq 6$ of 12 clinical criteria required or presence of MSU crystals in SF or in tophus.

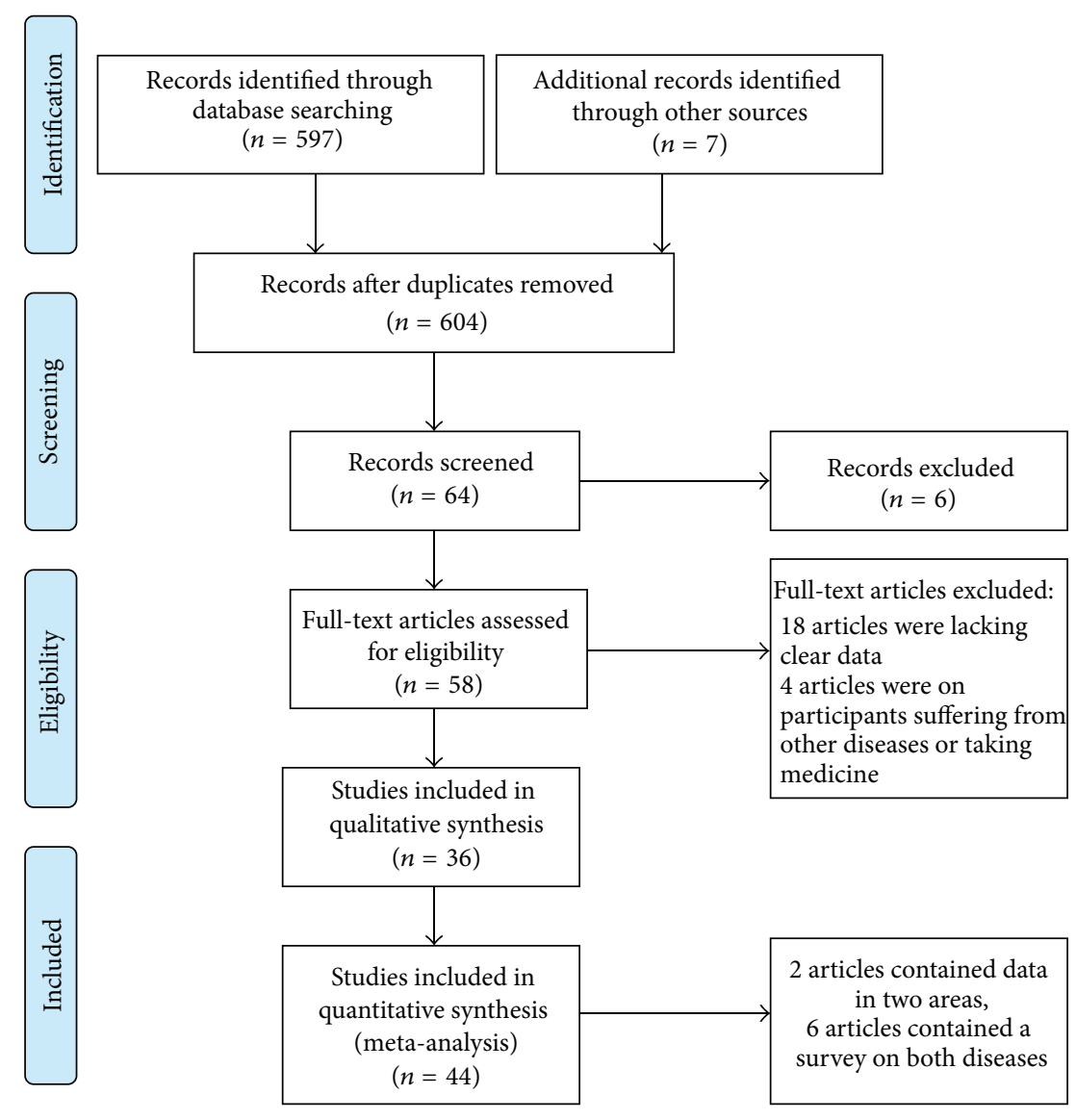

FIGURE 1: Flow diagram for the literature-search process.

hyperuricemia $\left(P<0.001, I^{2}=98 \%\right)$; however, the heterogeneity decreased in the subgroup analysis. We observed publication bias in both studies according to Egger's test. Then we performed a trim and fill method to address the problem of publication bias. However, it became unchanged after we applied the trim and fill method [65].

\section{Discussion}

We analyzed 44 epidemiological surveys covering 16 provinces, municipalities, and autonomous regions in mainland China. An important strength of our study is that it is a crosssectional study. We systematically analyzed the prevalence 


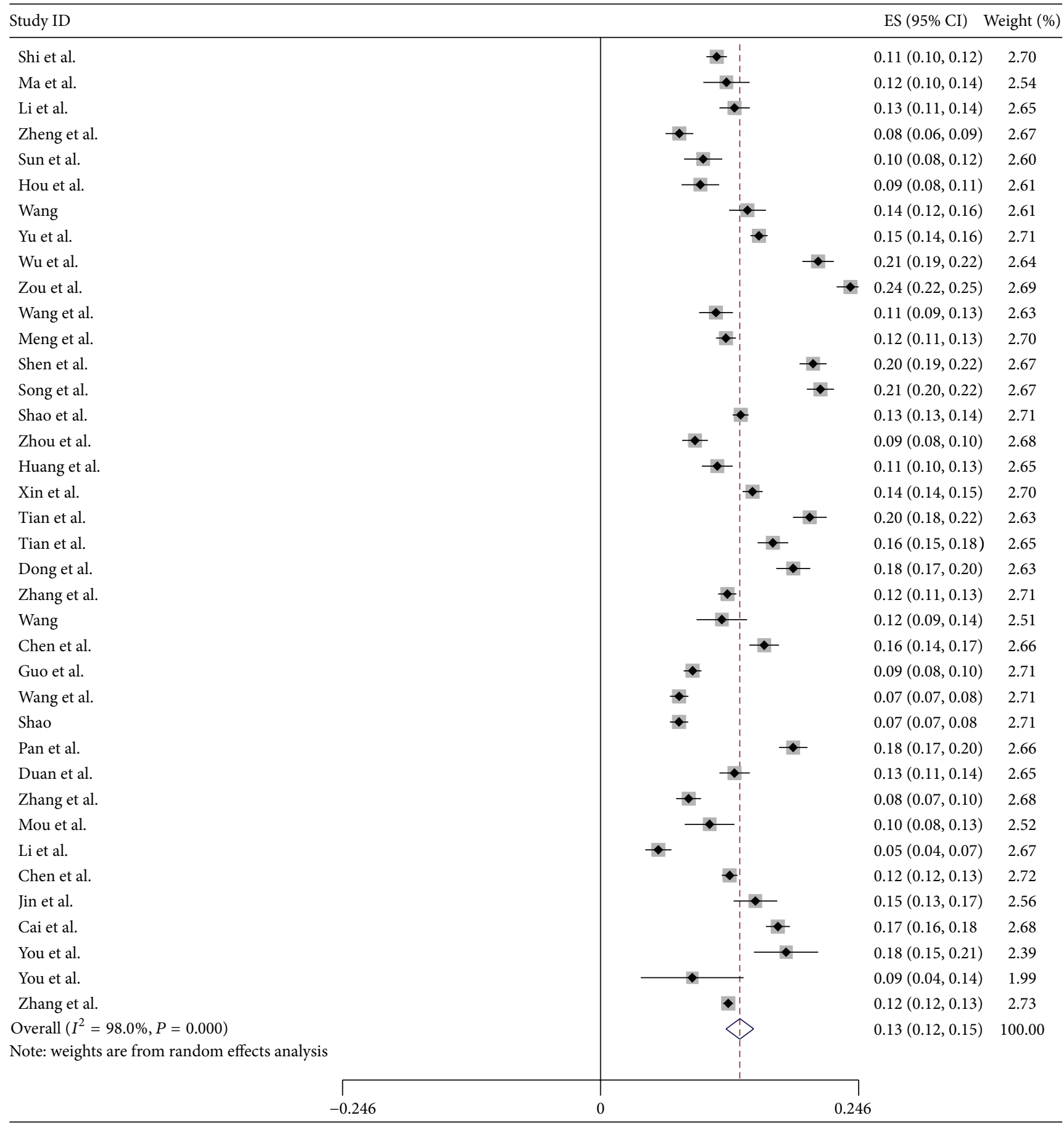

FIGURE 2: Forest plot of the pooled prevalence of hyperuricemia in mainland China.

of hyperuricemia and gout in mainland China. To our knowledge, this is the first study of this kind to focus on mainland China and cover the years from 2000 to 2014.

In our meta-analysis, the prevalence of hyperuricemia in mainland China was $13.3 \%$ (19.4\% in men and $7.9 \%$ in women), which was in accordance with the worldwide prevalence rate reported to be ranging from $2.6 \%$ to $36 \%$ in different populations [66]. Our result was lower than that observed in several developed countries, such as the United
States (21.2\% in men and $21.6 \%$ in women) [21] and Japan ( $25.8 \%$ overall, $34.5 \%$ in men and $11.6 \%$ in women) [67]. As expected, the prevalence is close to that in most developing countries; for example, it is $10.6 \%$ in Thailand $(18.4 \%$ in men and $7.8 \%$ in women) [68] and $12.1 \%$ in Turkey (19.0\% in men and 5.8\% in women) [69]. Chuang et al. performed the Nutrition and Health Survey in Taiwan (NAHSIT) study from 2005 to 2008, which focused on a Chinese population, but the results of their study differed significantly from those of our 


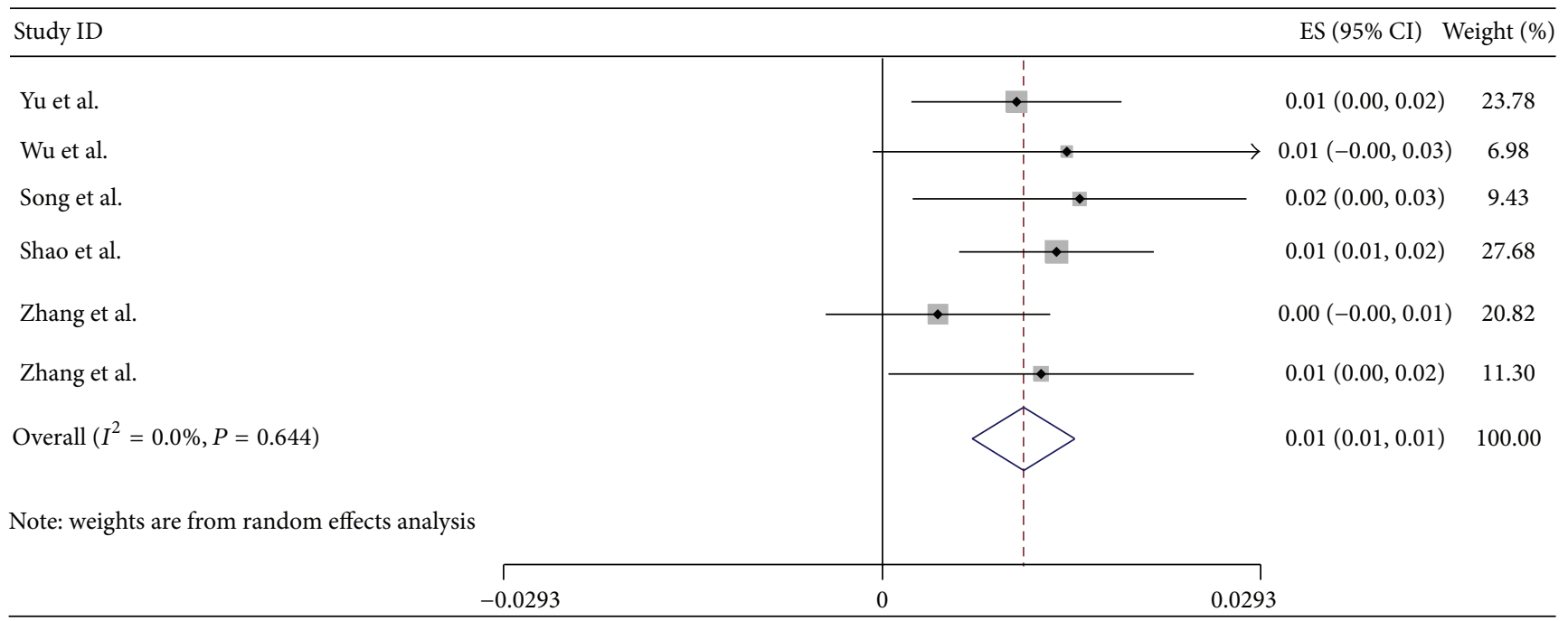

FIGURE 3: Forest plot of the pooled prevalence of gout in mainland China.

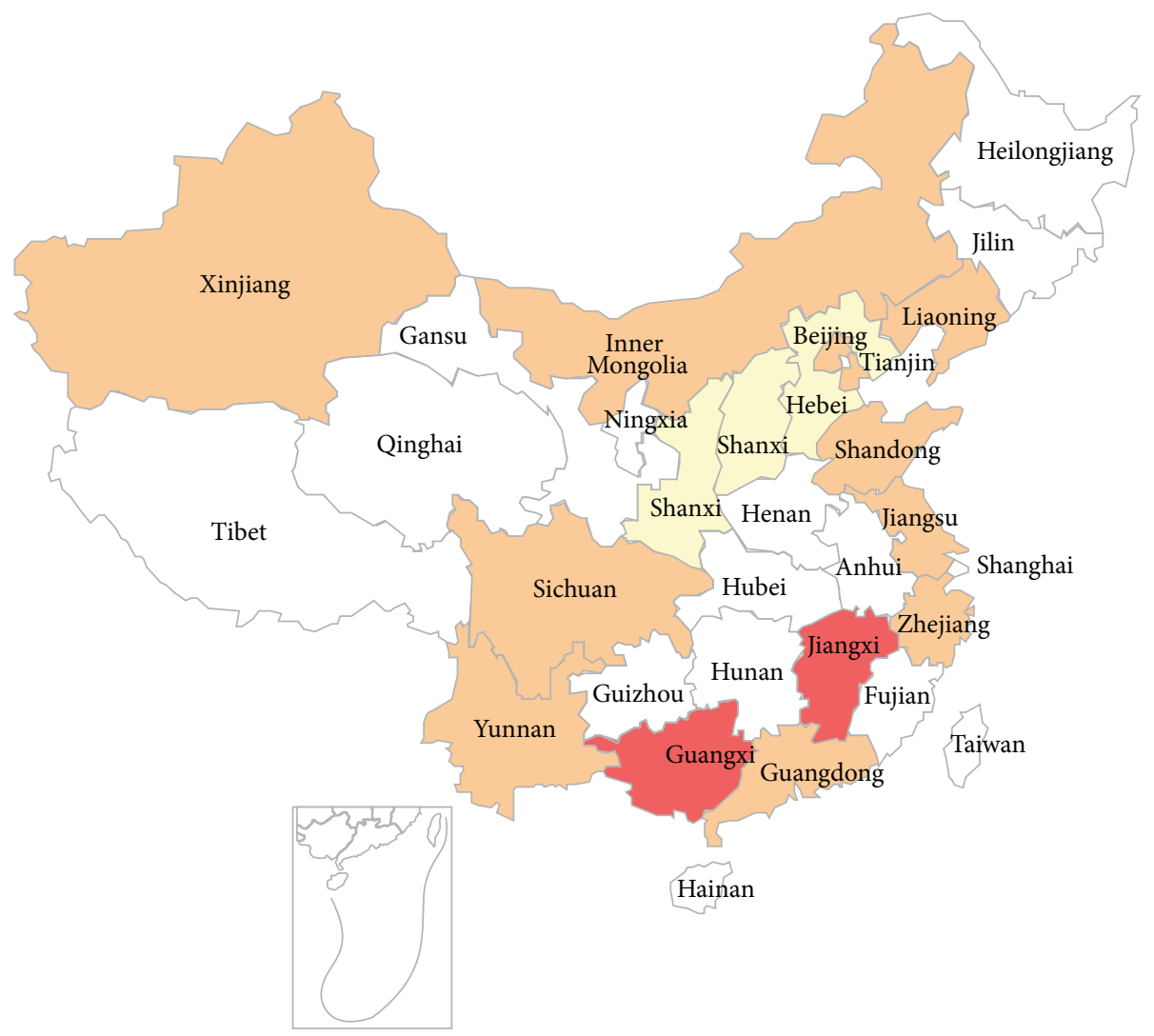

Prevalence estimate (\%)

$\begin{array}{ll}\square & \begin{array}{l}\text { No data } \\ <10 \%\end{array} \\ \square & >20 \%\end{array}$

FIGURE 4: Regional distribution of pooled prevalence of hyperuricemia in mainland China. 

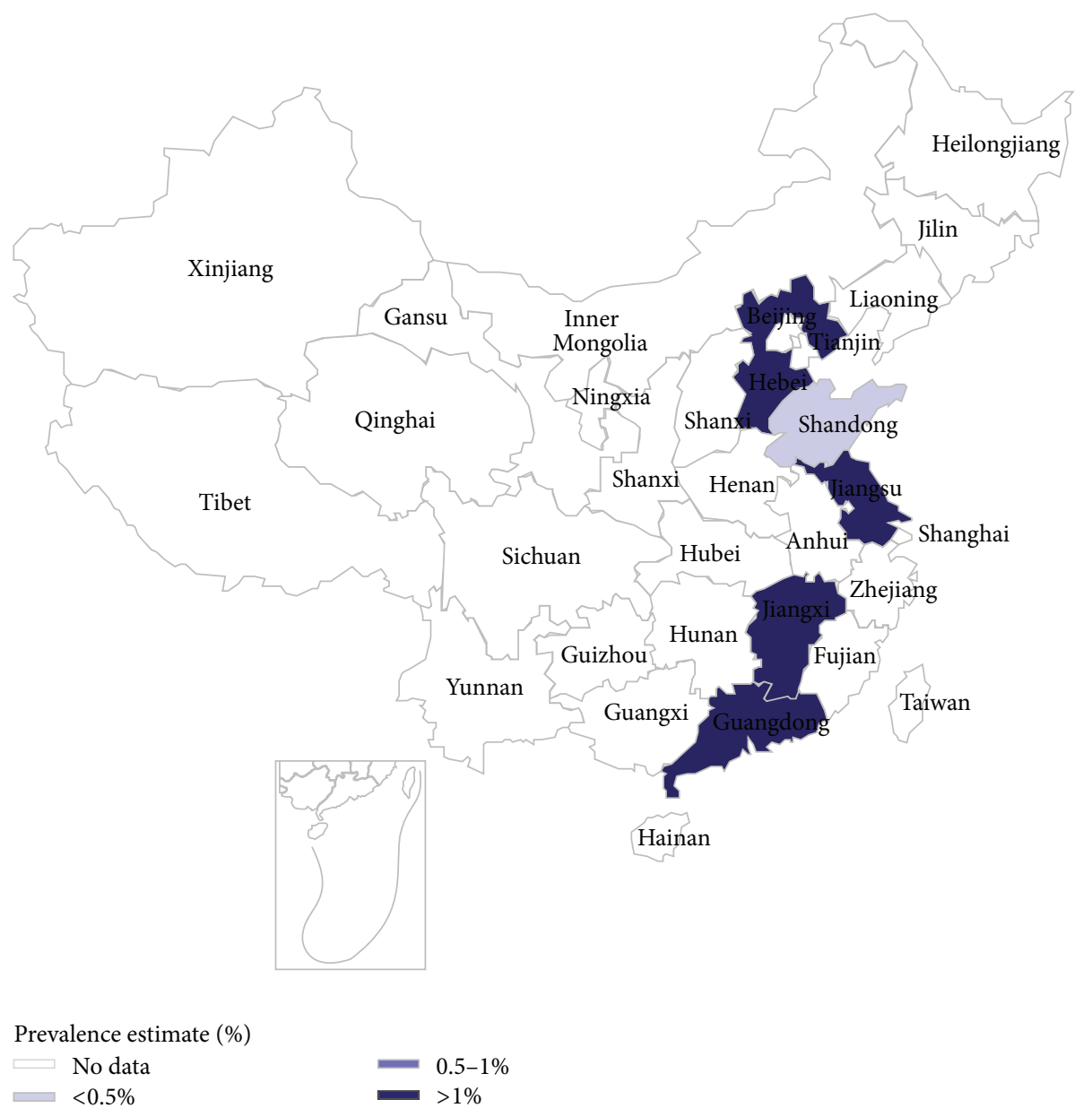

FIGURE 5: Regional distribution of pooled prevalence of gout in mainland China.

study. In their reports the prevalence of hyperuricemia was $21.6 \%$ in men and $9.6 \%$ in women [70], which was higher than ours and similar to that in developed countries. Our research was performed on mainland China, whereas Chuang's study was conducted in Taiwan, an economically-developed region in China. We believe that our results are more representative of the Chinese population living in the mainland.

As China is geographically vast, the prevalence of hyperuricemia varies significantly in different geographic regions. The prevalence in south China was $18.6 \%$, which is much higher than the pooled prevalence, followed by southwest China (13.9\%), north China (13.2\%), east China (12.9\%), northwest China (10.3\%), and northeast China (10.1\%). Such differences might be related to variability in lifestyle and economic development. As a previous study described, rapidly increasing economic development has led to unhealthy lifestyles [71]. Residents in south China, which is an economically developed region, consume more meat, seafood, and alcohol than residents elsewhere; therefore, the prevalence of hyperuricemia was higher in south China than in other regions. Also, hyperuricemia was more common in urban residents than in rural residents, and the inland prevalence of hyperuricemia was much higher than in coastal areas.
From our study, the pooled prevalence of gout was 1.1\%, which is similar to that in Italy (0.9\% in 2009) [19], France (0.9\% in 2013) [72], the United Kingdom, and Germany $(1.4 \%$ in 2000-2005) [17]. In addition, the prevalence of gout in our country was much higher than that in Turkey $(0.31 \%$ in $2001-$ 2002) [73], Mexico (0.3\% in 2011) [74], Greece (0.47\% in 2003) [75], and the Czech Republic (0.3\% in 2002-2003) [76] but is markedly lower than that in New Zealand (2.69\% in 20082009) [77], the USA (3.9\% in 2007-2008) [21], and Australia (9.7\% in 2002) [78].

Another main finding in our study was that the prevalence of gout in men $(1.5 \%)$ was remarkably higher than in women $(0.9 \%)$. This difference in sex was consistent with previous studies in other populations. Soriano et al. investigated the current epidemiology of gout in the general United Kingdom population and suggested that the incidence of gout was 4.42 per 1,000 persons per year in men and 1.32 per 1,000 persons per year in women [13]. Zhu et al. reported that the prevalence in the US was $5.9 \%$ in men, which was much higher than the $2.0 \%$ observed for women [21]. In accordance with these researches, prevalence of gout in Taiwan was $9.2 \%$ for men and $2.3 \%$ for women [70]. Sex hormones may explain the difference between the sexes. Ghei et al. suggested that the serum uric acid levels were higher 
TABLE 3: Stratified prevalence of hyperuricemia in mainland China.

\begin{tabular}{|c|c|c|c|c|c|}
\hline \multirow{2}{*}{ Subgroups } & \multirow{2}{*}{ Prevalence (\%) (95\% CI) } & \multirow{2}{*}{ Number of studies } & \multicolumn{2}{|c|}{ Heterogeneity } & \multirow{2}{*}{ Case/total } \\
\hline & & & $I^{2} \%$ & $P$ value & \\
\hline \multicolumn{6}{|l|}{ Area } \\
\hline Urban & $13.7(12.0,15.4)$ & 27 & 98.4 & $<0.001$ & $14322 / 101787$ \\
\hline Rural & $12.3(10.5,14.1)$ & 11 & 94.3 & $<0.001$ & $3154 / 24581$ \\
\hline \multicolumn{6}{|l|}{ Coastal/inland } \\
\hline Inland & $13.8(11.8,15.7)$ & 23 & 98.3 & $<0.001$ & $10160 / 68666$ \\
\hline Coast & $12.5(10.8,14.2)$ & 15 & 97.3 & $<0.001$ & $7316 / 57702$ \\
\hline \multicolumn{6}{|l|}{ Location } \\
\hline North China & $13.2(11.5,14.8)$ & 13 & 96.3 & $<0.001$ & $6162 / 48261$ \\
\hline East China & $12.9(10.2,15.6)$ & 12 & 98.6 & $<0.001$ & $5577 / 40857$ \\
\hline Northwest & $10.3(5.4,15.3)$ & 3 & 97.4 & $<0.001$ & $593 / 5382$ \\
\hline Northeast & $10.1(8.9,11.2)$ & 3 & 0.0 & 0.376 & $275 / 2720$ \\
\hline Southwest & $13.9(11.7,16.1)$ & 3 & 88.6 & $<0.001$ & $1533 / 11572$ \\
\hline South China & $18.6(13.8,23.3)$ & 4 & 98.3 & $<0.006$ & $3336 / 17576$ \\
\hline \multicolumn{6}{|l|}{ Economic level } \\
\hline High & $13.8(12.0,15.6)$ & 20 & 98.0 & $<0.001$ & $8094 / 59811$ \\
\hline Low & $12.6(10.6,14.7)$ & 18 & 98.1 & $<0.001$ & $9382 / 66557$ \\
\hline \multicolumn{6}{|l|}{ Sex } \\
\hline Male & $19.4(17.6,21.1)$ & 38 & 96.7 & $<0.001$ & $11644 / 60768$ \\
\hline Female & $7.9(6.6,9.3)$ & 38 & 97.9 & $<0.001$ & $5859 / 65654$ \\
\hline Total & $13.3(11.9,14.6)$ & 38 & 98.0 & $<0.001$ & $17476 / 126368$ \\
\hline
\end{tabular}

TABLE 4: Prevalence of gout in mainland China by different stratification factors.

\begin{tabular}{|c|c|c|c|c|c|}
\hline \multirow{2}{*}{ Subgroups } & \multirow{2}{*}{ Prevalence (\%) (95\% CI) } & \multirow{2}{*}{ Number of studies } & \multicolumn{2}{|c|}{ Heterogeneity } & \multirow{2}{*}{ Case/total } \\
\hline & & & $I^{2} \%$ & $P$ value & \\
\hline \multicolumn{6}{|l|}{ Area } \\
\hline Urban & $1.2(0.7,1.8)$ & 4 & 0.0 & 0.830 & $280 / 21764$ \\
\hline Rural & $0.9(0.2,1.6)$ & 2 & 14.0 & 0.313 & $49 / 7481$ \\
\hline \multicolumn{6}{|c|}{ Coastal/inland } \\
\hline Inland & $1.4(0.8,1.9)$ & 4 & 0.0 & 0.989 & $229 / 16470$ \\
\hline Coastal & $0.8(0.2,1.4)$ & 2 & 0.4 & 0.316 & $100 / 12775$ \\
\hline \multicolumn{6}{|l|}{ Study year } \\
\hline 2000-2005 & $0.9(0.0,1.8)$ & 2 & 59.1 & 0.118 & $128 / 13150$ \\
\hline 2006-2010 & $1.1(0.4,1.8)$ & 2 & 0.0 & 0.655 & $117 / 10191$ \\
\hline 2011-2014 & $1.4(0.5,2.2)$ & 2 & 0.0 & 0.737 & $84 / 5904$ \\
\hline \multicolumn{6}{|l|}{ Sex } \\
\hline Male & $1.5(0.8,2.1)$ & 6 & 1.9 & 0.404 & $226 / 14060$ \\
\hline Female & $0.9(0.0,1)$ & 6 & 0.0 & 0.924 & $78 / 15185$ \\
\hline Total & $1.1(0.7,1.5)$ & 6 & 0.0 & 0.644 & $329 / 29245$ \\
\hline
\end{tabular}

in men than in women and that this difference is under the influence of sex hormones. Uric acid levels in women tend to increase after menopause $[69,79]$.

Moreover, in line with previous results, a rise in the prevalence of gout was observed in the current study. The prevalence was $0.9 \%$ in $2000-2005,1.1 \%$ in $2006-2010$, and $1.4 \%$ in 2011-2014. The US National Health and Nutrition Examination Survey (NHANES) study conducted in 20072008 demonstrated that the prevalence of gout was $3.9 \%$, though it was only $2.7 \%$ in 1988-1994 [21]. The NAHSIT studies, carried out during 1993-1996 and 2005-2008, showed that the prevalence of gout increased from $4.7 \%$ to $8.2 \%$ in men and $2.2 \%$ to $2.3 \%$ in women [70]. To help reduce the increasing burden of these diseases, prospective data on modifiable risk factors in lifestyle and diet for these conditions should be considered including, but not limited to, weight control, regular exercise, restricted intake of meat and purine-rich foods, and avoidance of heavy drinking. 
Vitamin C supplementation may also be considered a longterm preventive measure as it can lower the risk of gout through lowering serum urate levels $[80,81]$.

Noteworthy, there is a lack of unified diagnostic criteria for gout, and several sets of criteria exist, such as the Rome criteria, the New York criteria, and the American Rheumatology Association (ARA) criteria [24]. The gold standard to diagnose gout is the presence of monosodium urate monohydrate (MSU) crystals in the synovial fluid (SF) at the time the patient experiences a gout attack [82]. The sets of criteria that include MSU crystals in SF have high specificity, and the exclusion of MSU crystal examination has led to a dramatic reduction in sensitivity [83]. However, MSU crystal examination is not always feasible in clinical practice. In 2015, Taylor et al. performed the Study for Updated Gout Classification Criteria (SUGAR) and determined ten parameters for accurately distinguishing gout from nongout [84]. In the same year, the American College of Rheumatology developed a new classification criteria for gout [85]. All the studies included in our analysis were performed from 2000 to 2014; therefore they were unable to adopt the new classification criteria. The diagnostic criteria used in this study could lead to a possible high sensitivity but low specificity. Because of this, the prevalence of gout in our analysis may be slightly higher than the actual rate, but it represents the general prevalence of gout and its geographical distribution in China.

Our meta-analysis has several other limitations. First, the pooled data covered only part of mainland China, especially for gout; however, our data did cover 16 provinces, municipalities, and autonomous regions. To our knowledge, it is the most encompassing cross-sectional study on hyperuricemia and gout prevalence in China. Second, the primary studies on hyperuricemia used different assays to assess serum uric acid levels with different reference intervals. Third, there were variations in the quality of the selected articles; hence heterogeneity may be influenced by uncertain data. Fourth, as much concern is given to this topic by Chinese doctors, the majority of the studies included were published in Chinese. However, this limitation was overcome by the current authors who are proficient in Chinese for interpretation and extraction of data. Also, sample size of included papers was too small in our subgroup analysis for the prevalence of gout, so there was no statistical power to explore the association between gout prevalence and geographic regions. Our work underlines the need for additional population-based investigations in the areas absent from our analysis. This is the first study to assess the nationwide epidemiology of hyperuricemia and gout in mainland China.

In conclusion, as previous studies were limited to specific regions, our study on the epidemiology of hyperuricemia and gout is of value to public health policies. Based on previous studies, we show that the prevalence of these diseases is high and that the rate of gout is rising. Consequently, large well-designed multicenter investigations are required in the future to provide information regarding the outcomes and prognosis of these chronic diseases in the entire population. Furthermore, effective measures should be adopted to prevent the increase in incidence of these diseases.

\section{Conflict of Interests}

The authors declare that there is no conflict of interests regarding the publication of this paper.

\section{Authors' Contribution}

Rui Liu and Cheng Han carried out the study. Rui Liu, Cheng Han and Di Wu wrote the main paper. Xinghai Xia and Jianqiu Gu prepared the figures and tables. Haixia Guan and Weiping Teng designed and funded the study. Zhongyan Shan revised the paper. All authors reviewed the paper. Rui Liu and Cheng Han contributed equally to this work.

\section{Acknowledgments}

The authors thank all the authors and participants in the studies mentioned in our research.

\section{References}

[1] S. Sinha, S. N. Singh, and U. S. Ray, "Total antioxidant status at high altitude in lowlanders and native highlanders: role of uric acid," High Altitude Medicine and Biology, vol. 10, no. 3, pp. 269270, 2009.

[2] M. Li, W. Hou, X. Zhang, L. Hu, and Z. Tang, "Hyperuricemia and risk of stroke: a systematic review and meta-analysis of prospective studies," Atherosclerosis, vol. 232, no. 2, pp. 265-270, 2014.

[3] B. Liu, T. Wang, H. N. Zhao et al., "The prevalence of hyperuricemia in China: a meta-analysis," BMC Public Health, vol. 11, article 832, 2011.

[4] N. Nakanishi, M. Okamoto, H. Yoshida, Y. Matsuo, K. Suzuki, and K. Tatara, "Serum uric acid and risk for development of hypertension and impaired fasting glucose or type II diabetes in Japanese male office workers," European Journal of Epidemiology, vol. 18, no. 6, pp. 523-530, 2003.

[5] R. J. Johnson, D.-H. Kang, D. Feig et al., "Is there a pathogenetic role for uric acid in hypertension and cardiovascular and renal disease?" Hypertension, vol. 41, no. 6, pp. 1183-1190, 2003.

[6] J. Wang, T. Qin, J. Chen et al., "Hyperuricemia and risk of incident hypertension: a systematic review and meta-analysis of observational studies," PLoS ONE, vol. 9, no. 12, Article ID el14259, 2014.

[7] M. J. Bos, P. J. Koudstaal, A. Hofman, J. C. M. Witteman, and M. M. B. Breteler, "Uric acid is a risk factor for myocardial infarction and stroke: the Rotterdam study," Stroke, vol. 37, no. 6, pp. 1503-1507, 2006.

[8] T.-C. Peng, C.-C. Wang, T.-W. Kao et al., "Relationship between hyperuricemia and lipid profiles in US adults," BioMed Research International, vol. 2015, Article ID 127596, 7 pages, 2015.

[9] H.-Y. Chang, C.-W. Tung, P.-H. Lee et al., "Hyperuricemia as an independent risk factor of chronic kidney disease in middleaged and elderly population," American Journal of the Medical Sciences, vol. 339, no. 6, pp. 509-515, 2010.

[10] D. I. Feig, D.-H. Kang, and R. J. Johnson, "Uric acid and cardiovascular risk," The New England Journal of Medicine, vol. 359, no. 17, pp. 1811-1821, 2008.

[11] D. Grassi, G. Desideri, A. V. Di Giacomantonio, P. Di Giosia, and C. Ferri, "Hyperuricemia and cardiovascular risk," High Blood 
Pressure and Cardiovascular Prevention, vol. 21, no. 4, pp. 235242, 2014.

[12] H. Huang, B. Huang, Y. Li et al., "Uric acid and risk of heart failure: a systematic review and meta-analysis," European Journal of Heart Failure, vol. 16, no. 1, pp. 15-24, 2014.

[13] L. C. Soriano, D. Rothenbacher, H. K. Choi, and L. A. García, "Contemporary epidemiology of gout in the UK general population," Arthritis Research and Therapy, vol. 13, no. 2, article R39, 2011.

[14] H. K. Choi, D. B. Mount, and A. M. Reginato, "Pathogenesis of gout," Annals of Internal Medicine, vol. 143, no. 7, pp. 499-516, 2005.

[15] A. J. Luk and P. A. Simkin, "Epidemiology of hyperuricemia and gout," American Journal of Managed Care, vol. 11, no. 15, supplement, pp. S435-S442, 2005.

[16] H. K. Choi, E. S. Ford, C. Li, and G. Curhan, "Prevalence of the metabolic syndrome in patients with gout: the Third National Health and Nutrition Examination Survey," Arthritis Care and Research, vol. 57, no. 1, pp. 109-115, 2007.

[17] L. Annemans, E. Spaepen, M. Gaskin et al., "Gout in the UK and Germany: prevalence, comorbidities and management in general practice 2000-2005," Annals of the Rheumatic Diseases, vol. 67, no. 7, pp. 960-966, 2008.

[18] E. Arromdee, C. J. Michet, C. S. Crowson, W. M. O’Fallon, and S. E. Gabriel, "Epidemiology of gout: is the incidence rising?" Journal of Rheumatology, vol. 29, no. 11, pp. 2403-2406, 2002.

[19] G. Trifirò, P. Morabito, L. Cavagna et al., "Epidemiology of gout and hyperuricaemia in Italy during the years 2005-2009: a nationwide population-based study," Annals of the Rheumatic Diseases, vol. 72, no. 5, pp. 694-700, 2013.

[20] P. Klemp, S. A. Stansfield, B. Castle, and M. C. Robertson, "Gout is on the increase in New Zealand," Annals of the Rheumatic Diseases, vol. 56, no. 1, pp. 22-26, 1997.

[21] Y. Zhu, B. J. Pandya, and H. K. Choi, "Prevalence of gout and hyperuricemia in the US general population: the National Health and Nutrition Examination Survey 2007-2008," Arthritis and Rheumatism, vol. 63, no. 10, pp. 3136-3141, 2011.

[22] A. E. Hak and H. K. Choi, "Lifestyle and gout," Current Opinion in Rheumatology, vol. 20, no. 2, pp. 179-186, 2008.

[23] F. Zhai, Y. He, G. Ma et al., "Study on the current status and trend of food consumption among Chinese population," Chinese Journal of Epidemiology, vol. 26, no. 7, pp. 485-488, 2005 (Chinese).

[24] S. L. Wallace, H. Robinson, A. T. Masi, J. L. Decker, D. J. McCarty, and T. F. Yü, "Preliminary criteria for the classification of the acute arthritis of primary gout," Arthritis and Rheumatism, vol. 20, no. 3, pp. 895-900, 1977.

[25] R. Roubenoff, "Gout and hyperuricemia," Rheumatic Disease Clinics of North America, vol. 16, no. 3, pp. 539-550, 1990.

[26] C. Han, X. He, X. Xia et al., "Subclinical hypothyroidism and type 2 diabetes: a systematic review and meta-analysis," PLoS ONE, vol. 10, no. 8, Article ID e0135233, 2015.

[27] J. P. T. Higgins, S. G. Thompson, J. J. Deeks, and D. G. Altman, "Measuring inconsistency in meta-analyses," British Medical Journal, vol. 327, no. 7414, pp. 557-560, 2003.

[28] W. Zhao, C. Han, X. Shi et al., "Prevalence of goiter and thyroid nodules before and after implementation of the Universal Salt Iodization program in mainland China from 1985 to 2014: a systematic review and meta-analysis," PLoS ONE, vol. 9, no. 10, Article ID e109549, 2014.
[29] P. Shi, P. Du, X. An et al., "Analysis of the relationship between serum uric acid levels and chronic diseases among residents in Shijingshan district, Beijing," Capital Journal of Public Health, vol. 7, no. 4, pp. 159-163, 2013 (Chinese).

[30] P. Ma, L. Chen, and P. Yang, "The correlation between hyperuricemia and metabolic syndrome in the residents in Xicheng district of Beijing," Tianjin Medical Journal, vol. 42, no. 7, pp. 722-724, 2014 (Chinese).

[31] D. Li, M. Ma, Y. Su et al., "The prevalence of hyperuricemia of bortala residents and its influencing factors," Modern Preventive Medicin, vol. 40, no. 9, pp. 1746-1748, 2013 (Chinese).

[32] J. Zheng, P. Chen, and J. Xie, "Analysis on prevalence rate and influential factors of hyperuricemia among residents in Ouhai District, Wenzhou," Zhejiang Preventive Medicine, vol. 22, no. 12, pp. 13-16, 2010 (Chinese).

[33] X. Sun, X. Wang, X. Pan et al., "Investigation of the prevalence and distributing feature of cardiovascular disease risk factors in Zhangzi island of Dalian," Chinese Journal of Cardiovascular Medicine, vol. 13, no. 4, pp. 280-283, 2008 (Chinese).

[34] G. Hou, L. Luo, L. Cheng, and Z. Gao, "Analysis on prevalence and influence factors of hyperuricemia among residents in Dalian Zhangzidao," The Journal of Medical Research, vol. 39, no. 2, pp. 37-40, 2010 (Chinese).

[35] R. Wang, "Analysis of urinary calculi in patients with hyperuricemia," Journal of Taishan Medical College, vol. 31, no. 4, pp. 300-301, 2010 (Chinese).

[36] J. W. Yu, T. G. Yang, W. X. Diao et al., "Epidemiological study on hyperuricemia and gout in Foshan areas, Guangdong province," Chinese Journal of Epidemiology, vol. 31, no. 8, pp. 860-862, 2010 (Chinese).

[37] W. Wu, J. Guo, W. Yang, Z. Zhong, Y. Liu, and H. Luo, "Epidemiology of hyperuricemia and gout in a community in Guangzhou," Chinese Journal of General Practice, vol. 6, no. 7, pp. 728-729, 2008 (Chinese).

[38] G. Zou, Y. Xiang, W. Che et al., "Prevalence of hyperuricemia in community residents of Xiangshan Disteict, Guilin City," Chinese Journal of Hypertension, vol. 19, no. 2, pp. 148-152, 2011 (Chinese).

[39] L. Wang, H. Fu, Y. Sun, and W. Cai, "A survey of metabolic syndrome and its related diseases in fishing village in island," Zhejiang Preventive Medicine, vol. 20, no. 10, pp. 8-9, 2008 (Chinese).

[40] J. Meng, Y. Zhu, W. Tan et al., "Prevalence of hyperuricemia in rural residents of Gaoyou City, Jiangsu Province," Chinese Journal of Rheumatology, vol. 16, no. 7, pp. 436-441, 2012.

[41] S. Shen, H. Li, Y. Feng et al., "Correlation between serum uric acid and metabolic syndrome of adults in Suxichang area of Jiangsu province," Chinese Journal of Prevention and Control of Chronic Diseases, vol. 22, no. 1, pp. 39-42, 2014 (Chinese).

[42] W. Song, J. Liu, Z. Chen, Y. Huo, A. Lin, and Y. Zhang, "Hyperuricemia and gout: a prevalence survey among over-40year-old community residents in Nanchang District," Chinese General Practice, vol. 17, no. 2, pp. 181-185, 2014 (Chinese).

[43] J. Shao, B. Mo, R. Yu, Z. Li, H. Li, and Y. Xu, "Epidemiological study on hyperuricemia and gout in community of Nanjing," Chinese Journal of Disease Control and Prevention, vol. 7, no. 4, pp. 305-308, 2003 (Chinese).

[44] F. Zhou, Q. Luo, L. Wu et al., "Epidemiological survey of chronic kidney disease among adults in Ningbo," Chinese Journal of Preventive Medicine, vol. 14, no. 9, pp. 669-674, 2013 (Chinese). 
[45] J. Huang, B. Zhou, S. Chen, and J. Dong, "A cross-sectional study on gout and hyperuricemia in community population," Zhejiang Journal of Preventive Medicine, vol. 25, no. 7, pp. 8-10, 2013 (Chinese).

[46] H. Xin, Q. Cao, F. Zhao et al., "Analysis on blood glucose, and blood lipid test results between hyperuricemia people and the general population," Preventive Medicine Tribune, vol. 17, no. 13, pp. 171-177, 2013 (Chinese).

[47] X. Tian, Z. Pang, G. Bao et al., "Ananlysis on prevalence and influence factors of hyperuricemia among residents in Qingdao," Chinese Journal of Public Health, vol. 24, no. 3, pp. 360-362, 2008 (Chinese).

[48] Y. Dong, H. Nan, and W. Gao, "Prevalence of the metabolic syndrome among adults aged 20-74 years in Zhanshan community of Qingdao," Chinese Journal of Diabetes, vol. 12, no. 2, pp. 177181, 2004 (Chinese).

[49] X. Zhang, W. Yu, L. Yu, L. Zhang, and Y. Yu, "An epidemiologic study on hyperuricaemia and gout in risidents of coastal areas of Haiyang City in Shangdong," Chinese Journal of General Practitioners, vol. 5, no. 4, pp. 216-219, 2006 (Chinese).

[50] X. Wang, "Analysis on prevalence and correlative factors of hyperuricemia among residents in Shenyang," in Proceedings of the 9th Annual Meeting of Chinese Society of Endocrinology, p. 46, 2010 (Chinese).

[51] X. Chen, Y. Zou, G. Li, Y. Xiao, and L. Wang, "Analysis on prevalence and influence factors of hyperuricemia among residents in Sichuan," Sichuan Medical Journal, vol. 29, no. 9, pp. 1267-1269, 2008 (Chinese).

[52] W. Guo, C. Xiao, X. Shen, G. Liu, and H. Zhang, "Prevalence of hyperuricemia and its relationship to hypertension, hyperglycemia and hyperlipidemia in community residents in Taiyuan city," Chinese Jeneral Practice, vol. 15, no. 9, pp. 30453047, 2012 (Chinese).

[53] J. Wang, Y. Shao, Y. Chen, H. Qian, and N. Zhang, "Analysis on Wenzhou citizen's hyperuricemia and the influence factor," Chinese Journal of Health Laboratory Technology, vol. 20, no. 10, pp. 2545-2547, 2010 (Chinese).

[54] Y. Shao, "Risk investigation on hyperuricemia among residents of two communities in Wenzhou City," Shanghai Journal of Preventive Medicine, vol. 23, no. 6, pp. 257-260, 2011 (Chinese).

[55] Y. Pan, D. Qiang, J. Ding, and Y. Shen, "Analysis on prevalencing of hyperuricemia and influence factors in Wujin District," Chinese Journal of Prevention and Control of Chronic NonCommunicable Disease, vol. 22, no. 3, pp. 315-317, 2014 (Chinese).

[56] W. Duan, J. Zhang, Y. Ma, and J. Cheng, "Prevalence and influencing factors of hyperuricemia among residents in Korla Region of Xinjiang," Chinese Jeneral Practice B, vol. 16, no. 3, 2013 (Chinese).

[57] P. Zhang, L. Zhang, C. Wang, S. Wei, and Q. Qiao, "Epidemiology of hyperuricemia and gout in Xingtai among adults over 30 years old," Practical Preventive Medicine, vol. 21, no. 8, pp. 1010-1012, 2014.

[58] S. Mou, C. Lv, J. Ju, Y. He, P. Guang, and Y. Ying, "Analusis of hyperuricemia of urban peasants," Chinese Primarhy Health Care, vol. 27, no. 6, pp. 66-67, 2013 (Chinese).

[59] S. Li, J. Yu, S. Lv, and Y. Zhang, "The prevalence and risk bactors of hyperuricaemia in Yan'an," Chinese Journal of Preventive Medicine, vol. 11, no. 8, pp. 763-765, 2010 (Chinese).

[60] X. Chen, H. Yang, and J. Yang, "Prevalence of hyperuricemia and gout among residents in Dali, Yunnan," China Practical Medical, vol. 4, no. 10, pp. 257-259, 2009 (Chinese).
[61] L. Jin, Y. Ma, R. Huang, J. Chen, H. Xiao, and X. Chen, "Epidemiology of hyperuricemia and influence factors among rural residents in Doumen District, Zhuhai," Chinese Community Doctors, vol. 11, no. 20, pp. 254-255, 2009 (Chinese).

[62] Z. Cai, X. Xu, X. Wu, C. Zhou, and D. Li, "Hyperuricemia and the metabolic syndrome in Hangzhou," Asia Pacific Journal of Clinical Nutrition, vol. 18, no. 1, pp. 81-87, 2009.

[63] L. You, A. Liu, G. Wuyun, H. Wu, and P. Wang, "Prevalence of hyperuricemia and the relationship between serum uric acid and metabolic syndrome in the Asian Mongolian area," Journal of Atherosclerosis and Thrombosis, vol. 21, no. 4, pp. 355-365, 2014.

[64] Q. Zhang, S. Lou, Z. Meng, and X. Ren, "Gender and age impacts on the correlations between hyperuricemia and metabolic syndrome in Chinese," Clinical Rheumatology, vol. 30, no. 6, pp. 777-787, 2011.

[65] S. R. Bapoje, A. Bahia, J. E. Hokanson et al., "Effects of mineralocorticoid receptor antagonists on the risk of sudden cardiac death in patients with left ventricular systolic dysfunction: a meta-analysis of randomized controlled trials," Circulation: Heart Failure, vol. 6, no. 2, pp. 166-173, 2013.

[66] S. Uaratanawong, S. Suraamornkul, S. Angkeaw, and R. Uaratanawong, "Prevalence of hyperuricemia in Bangkok population," Clinical Rheumatology, vol. 30, no. 7, pp. 887-893, 2011.

[67] K. Nagahama, K. Iseki, T. Inoue, T. Touma, Y. Ikemiya, and S. Takishita, "Hyperuricemia and cardiovascular risk factor clustering in a screened cohort in Okinawa, Japan," Hypertension Research, vol. 27, no. 4, pp. 227-233, 2004.

[68] V. Lohsoonthorn, B. Dhanamun, and M. A. Williams, "Prevalence of hyperuricemia and its relationship with metabolic syndrome in Thai adults receiving annual health exams," Archives of Medical Research, vol. 37, no. 7, pp. 883-889, 2006.

[69] I. Sari, S. Akar, B. Pakoz et al., "Hyperuricemia and its related factors in an urban population, Izmir, Turkey," Rheumatology International, vol. 29, no. 8, pp. 869-874, 2009.

[70] S.-Y. Chuang, S.-C. Lee, Y.-T. Hsieh, and W.-H. Pan, “Trends in hyperuricemia and gout prevalence: Nutrition and Health Survey in Taiwan from 1993-1996 to 2005-2008," Asia Pacific Journal of Clinical Nutrition, vol. 20, no. 2, pp. 301-308, 2011.

[71] L. Zhang, F. Wang, L. Wang et al., "Prevalence of chronic kidney disease in China: a cross-sectional survey," The Lancet, vol. 379, no. 9818, pp. 815-822, 2012.

[72] T. Bardin, S. Bouee, P. Clerson et al., "Prevalence of gout in the adult population of France," Arthritis Care \& Research, 2015.

[73] M. Birlik, O. Gurler, S. Akar, I. Sari, F. Onen, and N. Akkoc, "The prevalence of gout in an urban area of Izmir, Turkey: a population-based epidemiological study," International Journal of Clinical Practice, vol. 68, no. 6, pp. 775-782, 2014.

[74] J. Rodriguez-Amado, I. Peláez-Ballestas, L. H. Sanin et al., "Epidemiology of rheumatic diseases. A community-based study in urban and rural populations in the state of Nuevo Leon, Mexico," Journal of Rheumatology, vol. 38, no. 86, pp. 9-14, 2011.

[75] A. Andrianakos, P. Trontzas, F. Christoyannis et al., "Prevalence of rheumatic diseases in Greece: a cross-sectional population based epidemiological study, The ESORDIG Study," Journal of Rheumatology, vol. 30, no. 7, pp. 1589-1601, 2003.

[76] P. Hanova, K. Pavelka, C. Dosta, I. Holcatova, and H. Pikhart, "Epidemiology of rheumatoid arthritis, juvenile idiopathic arthritis and gout in two regions of the Czech Republic in a descriptive population-based survey in 2002-2003," Clinical \& Experimental Rheumatology, vol. 24, no. 5, pp. 499-507, 2006. 
[77] D. Winnard, C. Wright, W. J. Taylor et al., "National prevalence of gout derived from administrative health data in aotearoa New Zealand," Rheumatology, vol. 51, no. 5, pp. 901-909, 2012.

[78] P. C. Robinson, W. J. Taylor, and T. R. Merriman, "Systematic review of the prevalence of gout and hyperuricaemia in Australia," Internal Medicine Journal, vol. 42, no. 9, pp. 997-1007, 2012.

[79] M. Ghei, M. Mihailescu, and D. Levinson, "Pathogenesis of hyperuricemia: recent advances," Current Rheumatology Reports, vol. 4, no. 3, pp. 270-274, 2002.

[80] H. K. Choi, "A prescription for lifestyle change in patients with hyperuricemia and gout," Current Opinion in Rheumatology, vol. 22, no. 2, pp. 165-172, 2010.

[81] H. K. Choi, X. Gao, and G. Curhan, "Vitamin C intake and the risk of gout in men: a prospective study," Archives of Internal Medicine, vol. 169, no. 5, pp. 502-507, 2009.

[82] J. M. A. Wijnands, A. Boonen, I. C. W. Arts, P. C. Dagnelie, C. D. A. Stehouwer, and S. van der Linden, "Large epidemiologic studies of gout: challenges in diagnosis and diagnostic criteria," Current Rheumatology Reports, vol. 13, no. 2, pp. 167-174, 2011.

[83] W. J. Taylor, J. Fransen, N. Dalbeth et al., "Performance of classification criteria for gout in early and established disease," Annals of the Rheumatic Diseases, 2014.

[84] W. J. Taylor, J. Fransen, T. L. Jansen et al., "Study for updated gout classification criteria: identification of features to classify gout," Arthritis Care \& Research, vol. 67, no. 9, pp. 1304-1315, 2015.

[85] T. Neogi, T. L. Jansen, N. Dalbeth et al., "2015 Gout classification criteria: an American College of Rheumatology/European League Against Rheumatism collaborative initiative," Annals of the Rheumatic Diseases, vol. 74, no. 10, pp. 1789-1798, 2015. 


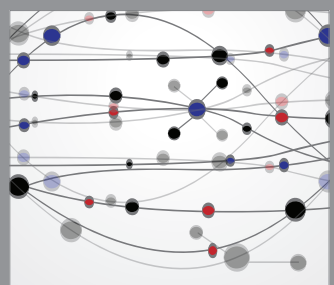

The Scientific World Journal
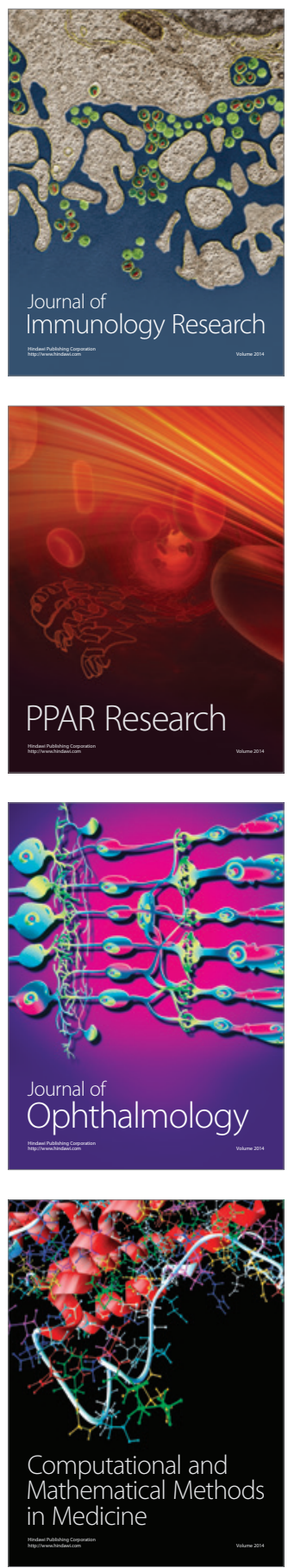

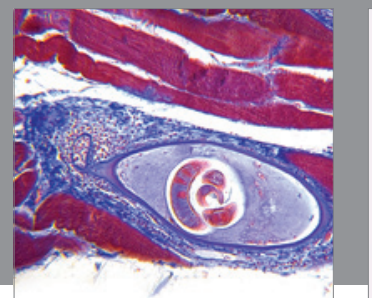

Gastroenterology

Research and Practice
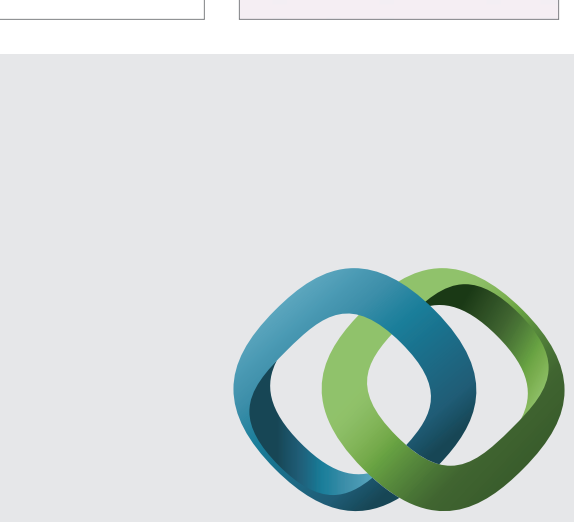

\section{Hindawi}

Submit your manuscripts at

http://www.hindawi.com
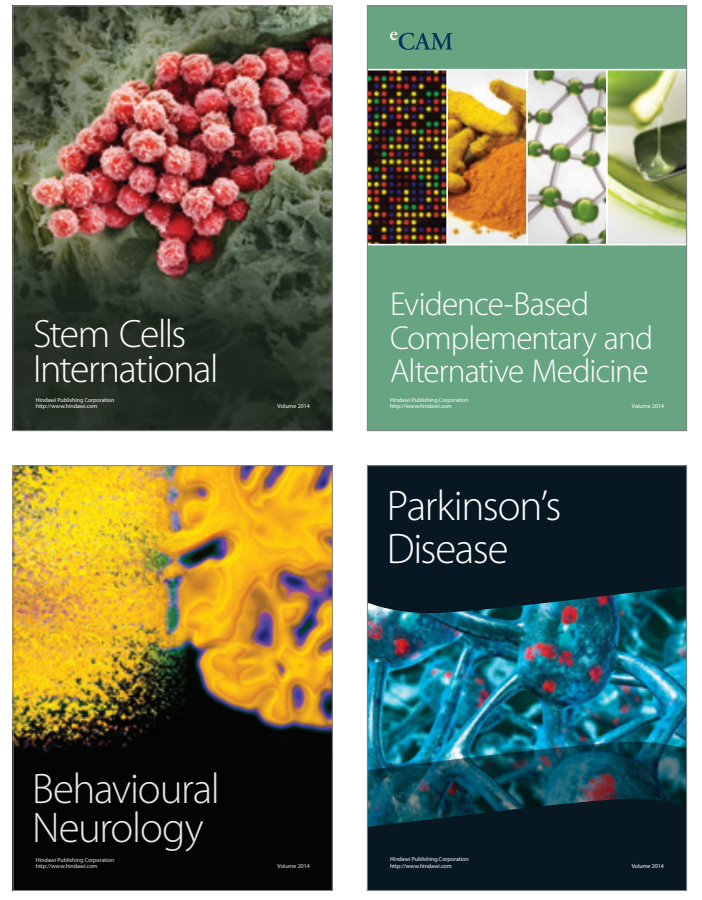
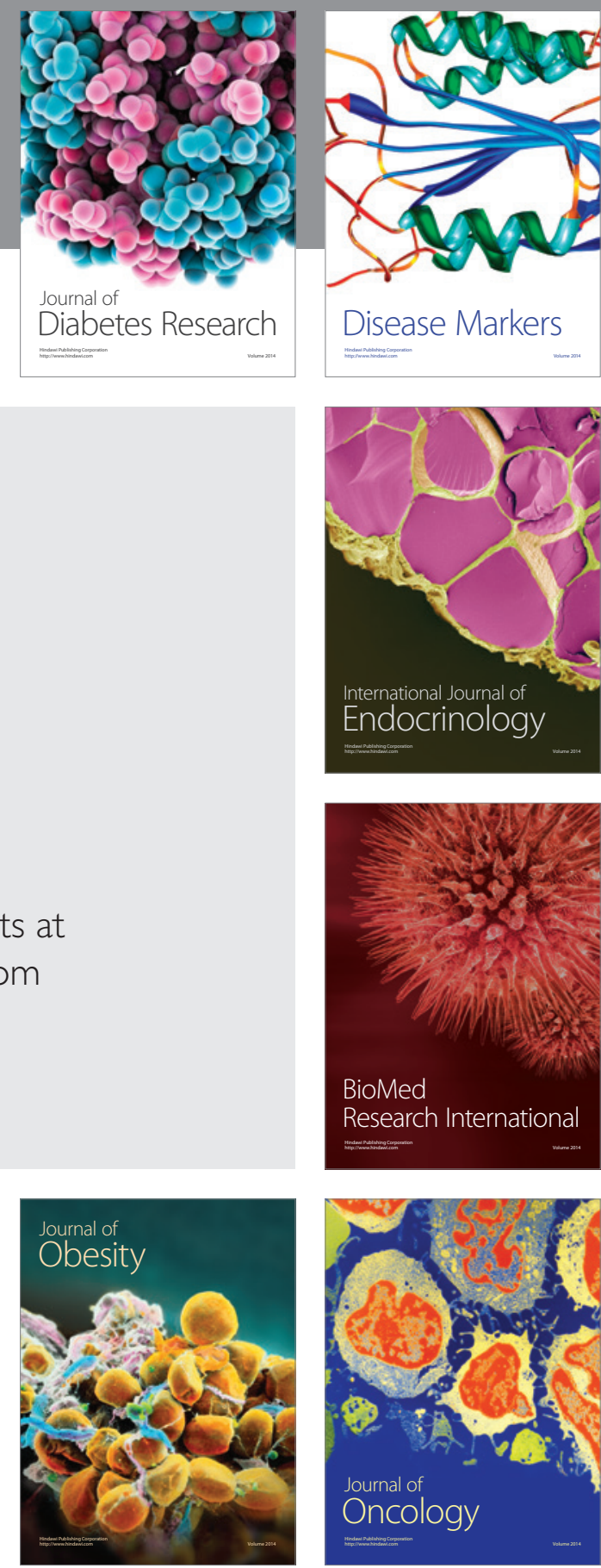

Disease Markers
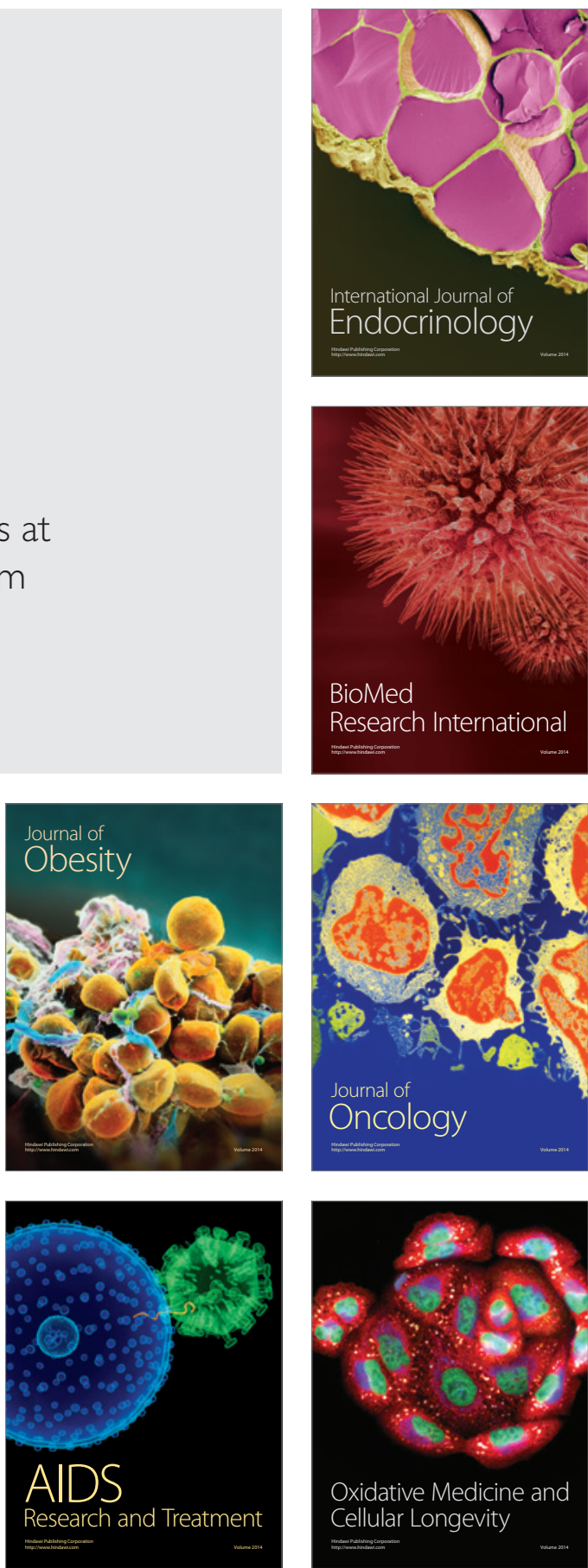